Research article

\title{
A dynamic management framework for socio-ecological system stewardship: A case study for the United States Bureau of Ocean Energy Management
}

\author{
Guillermo Auad $^{\mathrm{a}, *}$, Jonathan Blythe ${ }^{\mathrm{a}}$, Kim Coffman ${ }^{\mathrm{a}}$, Brian D. Fath ${ }^{\mathrm{b}, \mathrm{c}}$ \\ a United States Department of the Interior, Bureau of Ocean Energy Management, Sterling, VA,USA \\ ${ }^{\mathrm{b}}$ Towson University, Department of Biological Sciences, Towson University, Towson, MD, USA \\ ${ }^{c}$ Advanced Systems Analysis Program, International Institute for Applied Systems Analysis, Laxenburg, Austria
}

\section{A R T I C L E I N F O}

\section{Keywords:}

Management framework

Resilience

Socio-ecological system

Adaptive governance

Decision making

Panarchy

Iterative scenarios

\begin{abstract}
A B S T R A C T
An effective and efficient stewardship of natural resources requires consistency across all decision-informing approaches and components involved, i.e., managerial, governmental, political, and legal. To achieve this consistency, these elements must be aligned under an overarching management goal that is consistent with current and well-accepted knowledge. In this article, we investigate the adoption by the US Bureau of Ocean Energy Management of an environmental resilience-centered system that manages for resilience of marine ecological resources and its associated social elements. Although the framework is generally tailored for this Bureau, it could also be adapted to other federal or non-federal organizations. This paper presents a dynamic framework that regards change as an inherent element of the socio-ecological system in which management structures, e.g., federal agencies, are embedded. The overall functioning of the management framework being considered seeks to mimic and anticipate environmental change in line with well-accepted elements of resilience-thinking. We also investigate the goal of using management for resilience as a platform to enhance socioecological sustainability by setting specific performance metrics embedded in pre-defined and desired social and/or ecological scenarios. Dynamic management frameworks that couple social and ecological systems as described in this paper can facilitate the efficient and effective utilization of resources, reduce uncertainty for decision and policy makers, and lead to more defensible decisions on resources.
\end{abstract}

\section{Introduction}

Managing natural resources is a critical endeavor for national governments. A success factor depends on the structures in place in those governance organizations and the recognition that those institutions themselves are systems that have material and social dimensions, bringing them into the class of systems referred to as socio-ecological systems. Social entities play a critical role in the socio-ecological system (SES) concept that was defined decades ago (Hollingshead, 1940) and can act with great influence to couple the social and ecological subsystems as part of a single, integrated overarching system that also includes the physical environment. Since then, and particularly after the early 2000s, there has been growth in addressing environmental issues by considering SESs (Andersson and Ostrom, 2008). More recently, this conceptual approach has been emphasized by many researchers (e.g., Guerrero and Wilson, 2017; Kok et al., 2016), as well as in high-level documents created with input from the international community, such as the peer-reviewed reports from the Intergovernmental Panel on Climate Change (Pachauri et al., 2014), the Laudato Si encyclical on the environment (Francis, 2015), and the Arctic Resilience Report (Arctic Council, 2016). We examine how management entities are hardwired to the ecological system that they manage and how the managerial (social) subsystem part of a given SES may be structured to function in a manner consistent with the natural system under consideration.

Scientists and policy makers in United States (US) federal, state, and local agencies are currently facing a number of challenges when managing natural resources while pursuing their respective missions. First, these agencies operate at different scales and have different geographical jurisdictions, and their responsibilities were set decades ago. These geographical jurisdictions often overlap or are in close proximity in such a way that managed environments, or even parts of them, often occupy more than one geographical jurisdiction and therefore are affected by management decisions from more than one

\footnotetext{
* Corresponding author.

E-mail addresses: guillermo.auad@boem.gov (G. Auad), jonathan.blythe@boem.gov (J. Blythe), kim.coffman@boem.gov (K. Coffman), bfath@towson.edu (B.D. Fath).
} 
organization. In addition, some federal agencies are responsible for the study and management of population units througout their ranges (e.g., tagging permits for scientific research, hunting and fishing permits/licenses), but they do not fully regard the associated environments.

Second, there are legal challenges, because most current environmental legislation, such as the Endangered Species Act and the National Environmental Policy Act (NEPA), has its roots in outdated knowledge, e.g., Benson and Garmestani, 2011a,b; Craig, 2013; Craig and Ruhl, 2014; Garmestani et al., 2013. These legislative actions took place before ecological concepts such as resilience, biodiversity, climate shifts, and scale discrimination became accepted as key factors affecting the environments over which different agencies have jurisdiction and decision-making power.

A third challenge is that some agencies lack the overarching management goal of aligning current and past knowledge (generated by them or others) in a common direction and organizing it in a way that is consistent with their mandated activities. This situation makes it difficult for management, governance, internal structure, legal, and policy considerations to be aligned and consistent with temporally dependent environmental stewardship priorities of all pertinent organizations, federal and otherwise.

These challenges are not new, and other challenges certainly exist, but a simple fact that we highlight throughout this paper is that the definition of environmental systems and their components affects the resulting environmental outcomes from natural resource management activities. Therefore, it is important to carefully consider the definitions of environmental systems and their components.

In the 2010-2011 timeframe, the former Mineral Management Service (MMS) was reorganized into three smaller agencies, with one of those three being the new Bureau of Ocean Energy Management (BOEM), whose mission is to manage development of US Outer Continental Shelf (OCS) energy and mineral resources in an environmentally and economically responsible way. BOEM is a regulatory agency with geographical jurisdiction in US federal waters, theOCS, which includes all submerged lands, subsoil, and seabed lying between the seaward extent of the states' jurisdiction and the seaward extent of federal jurisdiction BOEM hosts three main programs: oil and gas, renewable energy, and marine minerals. BOEM's responsibility includes using the best available information to inform its decision-making process while following existing legislation, e.g., the NEPA and the OCS Lands Act. The oil and gas program creates a mandated-by-law Five-Year Program for oil and gas development, which establishes a schedule of oil and gas lease sales proposed for planning areas of the US OCS. The program specifies the size, timing, and location of potential leasing activity that the Secretary of the Interior determines will best meet national energy needs while balancing stewardship of the environment. BOEM conducts necessary environmental studies and prepares required environmental documents, and consults with states, tribes, and the general public. Based on this information, BOEM proceeds with its oil and gas leasing decisions on offshore energy. The renewable energy program is in charge of the environmental compliance aspects in connection with the offshore installation or deployment of equipment, devices, and infrastructure able to generate and transport electricity from renewable sources of energy, such as wind, wave, and ocean currents energy. The marine minerals program addresses issues of coastal erosion in state areas by transplanting sand and gravel from federal waters to eroded beaches.

A broad description of the path followed by traditional and scientific knowledges within the BOEM structure is given in Kendall et al. (2017) where they define traditional knowledge as a body of evolving practical knowledge based on observations and personal experience of indigenous residents over an extensive, multi-generational time period (BOEM, 2012). In Kendall's paper the authors specifically focus on how traditional/indigenous knowledge can enter the streamlined path of BOEM's process at six different stages or entry points, and where consideration of physical, chemical, socio-economic, and biological information enter this path after BOEM's Environmental Studies Program

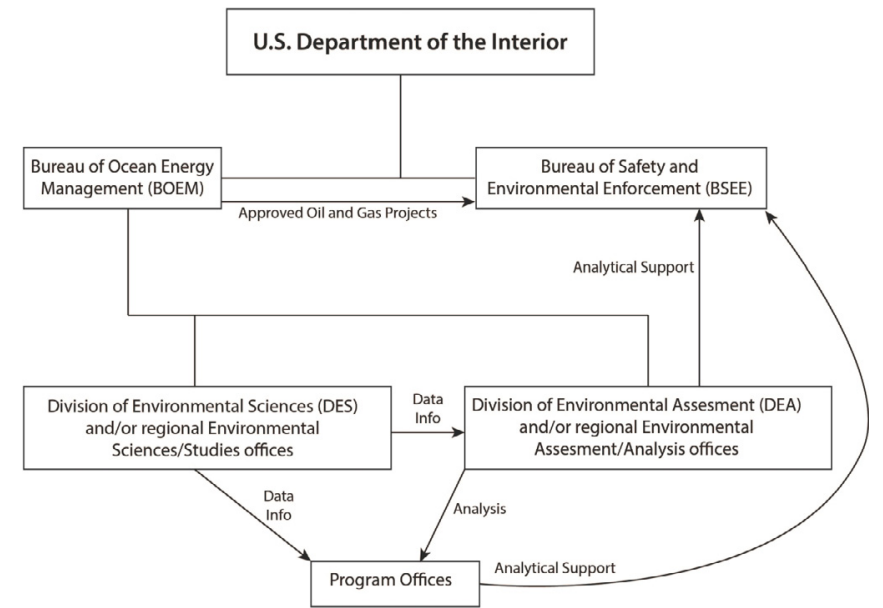

Fig. 1. Relationship among offices and bureaus. BOEM and the Bureau of Environmental Safety and Enforcement (BSEE) are the two agencies within the U.S. Department of the Interior (DOI) charged with managing marine energy and mineral resources (BOEM) and resource extraction operations (BSEE). Within BOEM, DES oversees the ESP at the headquarters level, and local environmental sciences/studies offices oversee the ESP at the regional level. DES and the regional sciences/studies offices provide data to DEA and regional environmental assessment/analysis offices. All of these provide data, analyses, and other information to the program offices (including the Economics Division in headquarters). DEA, the regional environmental assessment/analysis offices, and the program offices all provide information to BOEM and/or DOI decision makers, as appropriate. When the lengthy process of auctioning offshore oil and gas leases and approving individual projects is complete, authority passes from BOEM to BSEE, which regulates safety and environmental protection during the operations phase. BOEM's environmental offices and Economics Division often work with BSEE to support analyses and decisions. Connectors without arrowheads represent organizational structure.

(ESP) scientists and managers identify information needs on an annual basis. The last stage in that path is commonly a decision on offshore energy, e.g., leasing decisions, permits, notice to lessees, among others. Along the path, they describe the ESP, which includes the Division of Environmental Sciences (DES) and regional studies sections, which collect and evaluate existing environmental information that the Division of Environmental Assessment (DEA), in coordination with regional assessment sections, uses to prepare legally required environmental documents, such as environmental impact statements (EISs) and environmental assessments (EAs). Ultimately, the Leasing Division coordinates the analyses and data in these documents, along with information on strategic resources (typically geophysical information from below the seafloor), to inform decisions at the highest levels which include lease sales for oil and gas development, conducted by BOEM's regional offices (Fig. 1). Generally, resources associated with different program needs include geophysical data (oil \& gas program), sand and gravel availability (Marine Minerals Program), and speed and direction of wind, waves, and currents for different locations and seasons (renewable energy program).

Currently, DES makes decisions on which research activities to conduct within a recently defined strategic framework, inspired by the present work, and based on the bureau's information needs in light of upcoming potential decisions. Use-inspired studies are driven by the needs of DEA and regional assessment sections, or information requirements created by such sources as high-level directives, new legislation, or executive orders from the US President or the Secretary of the Interior. Based on existing information needs, defined within this strategic framework, higher-priority studies are designed, and BOEM then announces requests for proposals. Technical review panels select from among the proposals submitted by academic, private, governmental, and non-governmental organizations. In this manner, the research that will inform decisions is conducted by third parties. 
Proceeding to address the contemporary challenges listed above, from the BOEM perspective, the following objectives are set, and will be addressed throughout the rest of this article in order to seek efficacy and efficiency as key properties of the framework defined below,

1. Reduce the uncertainty of socio-ecological knowledge through a continuous learning process (efficacy)

2. Couple management operability and decisions with environmental dynamics and changing socio-ecological conditions (efficacy)

3. Reduce risk by focusing research efforts on vulnerable areas/components/processes of the SES under consideration (efficacy) where we note that, in this article, vulnerability is defined by generalizing the definition of the IPCC (McCarty et al., 2001), as the degree to which a system is susceptible to, or unable to cope with, adverse effects such as those of external drivers

4. Anticipate change as new information arrives (efficacy and efficiency)

5. Develop dynamic policies while recognizing the need for adopting (Garmestani et al., 2013) reflexive laws, providing a solid foundation for those policies (efficiency)

This article pursues the critical analysis needed to address the three challenges noted above and makes suggestions toward a practical pathway forward to evaluate the environmental mission of BOEM. In what follows we present a pathway to move forward while introducing some elements and useful definitions that will define the environmental management framework. Finally we provide two practical examples that could test the operability of the framework with specific directives generated internally or externally. In the end discussions and conclusions are presented as well as an outlook for future work.

\section{A pathway to address current challenges}

Managerial organizations are here treated as the system under study and as such will exhibit properties similar to those characterizing natural systems (Goerner et al., 2015) and which understanding in structure and function is vital for addressing complex SES issues (Ball, 2017). These issues include the need for institutional and stakeholder diversity, which suggests that building resilience into the system requires 'designing complexity to govern complexity' (Ostrom, 1998). This is a first step to understand the dynamics of SESs and to achieve nature-like efficiency when considering their behavior and properties. Although these organizational structures are very relevant to support functioning and internal processes, it is also important to select an effective dynamics or internal functioning in order to deliver efficient and effective management decisions. This is why it is vital for organizations charged with natural resource management to synchronize their functioning with that of the natural environment being considered while having an efficient internal communication system, e.g., good decisions made today might not be appropriate later in time. This synchronicity thus provides the necessary synergies and dynamics that will support defensible decisions in natural resource management. It is now important to visualize these concepts through a robust model that is able to encapsulate and properly represent the challenges and objectives noted in the Introduction section.

Based on these concepts, we therefore argue that to achieve an effective coupling between management entities (humans only) and ecological systems (which include humans and other species), it is necessary to align their elements under a "guiding beacon," or management goal, that contemplates minimal or no disruption of ecosystem structure and function. Because all ecosystems possess a powerful property that protects them against internal or external stressors and impacts - resilience-it is then minimally disruptive to preserve this natural and very powerful shield. The concept of resilience was initially presented by Holling (1973) and has become a seminal element within the field of ecology that has been transferred to other fields for different

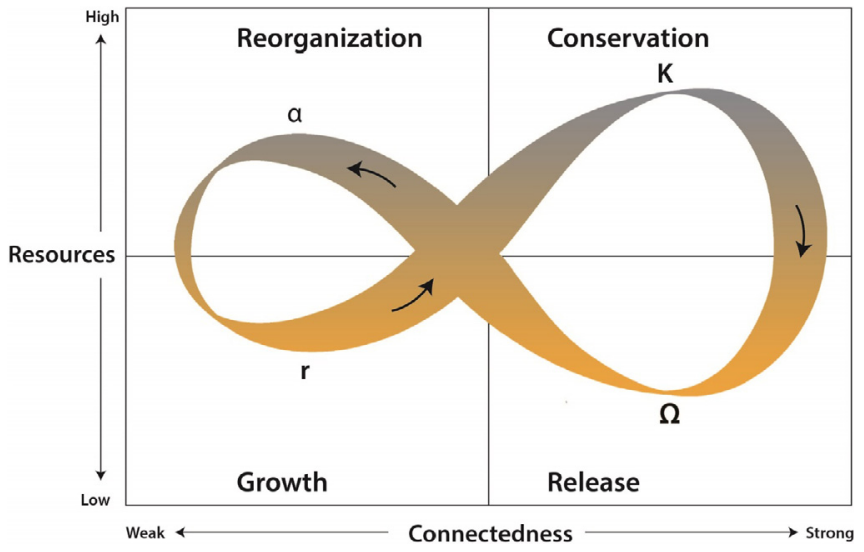

Fig. 2. The adaptive cycle as defined by Holling (1986). Four stages characterize the state of functioning of a given social, ecological, or socio-ecological system: 1) growth (r-stage), 2) stability or status quo (conservation, K-stage), 3) release or collapse (but not total destruction, $\Omega$-stage), and 4) reorganization ( $\alpha$-stage). The cycle restarts with a new growth phase.

purposes, with different authors providing different definitions.

In order to address the challenges noted in the Introduction, we must first introduce a few fundamental concepts that will pave the way to develop a practical and effective management and governance framework. Although in general terms resilience is the ability or property of a system to keep functioning despite stressors or shocks (internal or external), in this paper we use the definition of resilience of Fath et al. (2015) as the ability of a system to remain on its current adaptive cycle path. This cycle (shown in Fig. 2) was proposed by Holling (1986) and has been extensively described and used since then, e.g., Gunderson and Holling (2002), Beier et al. (2009).

We use four different variables or properties as the key components that contribute to the resilience of a given SES: a) connectivity, b) diversity (of species and genetic), c) flexibility, and d) redundancy which all contribute to maintain a given system navigating on the path (Fig. 2) of its adaptive cycle (Fath et al., 2015). Connectivity refers to both trophic and non-trophic relations among different species and also to the connectivity of different species to different resources such as water and shelter. Diversity refers to the variation within (genes) and across species in an ecosystem, and more diversity often increases resilience. Flexibility refers to the ability of all components of an SES to satisfy basic needs (such as food) by using alternative sources, which in some cases also requires flexibility in behavior. Related to flexibility is redundancy, where different elements of the SES are interchangeable, e.g., for example if a predator depends on several prey species at the same time, its population vital rates would be minimally affected even if one of them were to become extinct..

Resilience is difficult to quantify (Kharrazi et al., 2016); however, it has been shown that some range of intermediate values is desirable in order to keep the state of a given SES in a region of high, and ideally maximum, sustainability (Goerner et al., 2015) while also considering the caveats noted by Benson and Craig (2014) on the evolution of the concept of sustainability over time. Therefore, resilience is a pre-condition for sustainability, although it is not itself a suitable foundation for a desired normative approach. Once resilience has been addressed, a decision-informing methodology is further necessary to make this information actionable, so decisions can be made, tracked, and studied in order to prevent impacting vulnerable elements and/or processes of the managed SES. Through this process, a desired state and associated outcomes are selected (Anderies et al., 2013), and the governing entity can then focus its resources and interventions to sustain those desired stages of operability. In this paper, we use their definition where sustainability involves a general knowledge about the dynamics of coupled SESs and the creative application of that knowledge to design both 
physical and governance infrastructure to conform to the collectively determined performance measures. Future investments can be efficiently dedicated to understand key aspects and vulnerabilities of the SES under consideration, so management decisions can be revisited to lower uncertainty and risk over time

The seven resilience principles listed below (Biggs et al., 2012) are adopted and considered throughout the rest of this article as they have a direct application to programs tasked with the stewardship of SESs, providing a practical guide for research and governance structuring. It is therefore important for these programs to focus their efforts to:

1. Maintain diversity as this is one of the key properties of resilience

2. Manage connectivity as it has a double edge and can propagate desirable and non-desirable information/properties

3. Manage slow variables and internal feedbacks of the SES under consideration, as both will provide the skeleton and the skin of most SESs (where slow variables shape or influence how a fast variable, i.e., those of primary concern to ecosystem users, responds to variations in one or more external drivers, e.g. Walker et al., 2012)

4. Foster adaptive complex thinking in order to produce management responses that are consistent with the dynamics and complexity of an SES under consideration

5. Encourage learning, which is a key element present in all the components of the framework being proposed in this article, i.e., adaptive governance and management, strategic reframing, dynamic policies (Fennell and Dowling, 2003), and which is also intrinsic to the design of the adaptive cycle, as it will tend to develop willingness by different participants

6. Broaden stakeholder participation to unveil unseen pathways while building trust and consensus

7. Promote a polycentric governance approach to create a structure that effectively facilitates the coordination and consistency in management decisions by multiple entities and the transmittal of information as in the natural systems mentioned by Goerner et al. (2015).

In BOEM's case, this last principle directly translates to considering traditional/indigenous knowledge in both research and decision making (Berkes, 2009; Eicken et al., 2011; Kendall et al., 2017), which the bureau has been doing for decades. An advantage of these seven elements is that they are mostly modular and can be implemented sequentially or all at once. Relatively simple actions can be identified for each element and tailored to the specific characteristics of the particular entity aiming to manage for resilience. Further, it has to be kept in mind that legal considerations come into play at specific insertion points, which will be illustrated and discussed below.

The concepts of resilience and sustainability will be used in connection with the SESs in which BOEM makes decisions on natural resources while exhibiting some level of internal flexibility and connectivity, i.e., inter-division communication (horizontal) and scientistpolicy maker interaction (vertical), among other elements. Our working hypothesis is that improvements, specifically an increase in efficiency and efficacy, can be made to the existing model, as noted by Kendall et al. (2017) who advocate for a more dynamic framework for BOEM, after we align and/or change existing practices in a manner consistent with resilience-thinking (Benson and Craig, 2014), while simultaneously aiming to maximize the sustainability of the SES under consideration.

Conceptually, said dynamic framework is needed to inform decisions by drawing upon fundamental scientific and traditional knowledges, and to help navigate through an always-changing socio-ecological landscape. Such a process would convey defensible decisions based on its internal and external hardwiring, as all components will consistently interlock while allowing consideration of other knowledge systems, e.g., indigenous knowledge (Berkes, 2009; Berkes et al., 2000; Kendall et al., 2017). This dynamic framework can be conceptualized as a vehicle facilitating navigation through the different stages of a given adaptive cycle, and it could be fine-tuned to enhance resilience characteristics of the SES in which BOEM operates, such as connectivity, diversity, flexibility, and redundancy, while also maintaining in place and expanding some existing approaches that promote sustainability. Therefore, such a framework should include the following:

1. Setting an overarching management goal would link the narrative among different studies, horizontally among simultaneous research activities and vertically among present and past findings. This would also facilitate the visualization of the larger SES and the identification of new research challenges. It will also create a favorable setting for addressing other issues such as scale discrimination and cross-scale processes.

2. Systematically tracking information would reduce uncertainty in monitoring environmental issues and the impact of decisions. It is emphasized that a one-way communication model where scientific information only moves up is obsolete and ineffective to reduce uncertainty and increase efficacy (Cvitanovic et al., 2015) and, as a result, there is a need for a two-way exchange of information model that can help direct the course of BOEM's deliberations as it arrives at decisions. Overcoming this and other challenges would be instrumental in visualizing and later addressing cross-scale problems that are key for effective natural resource management.

3. Developing detailed multi-entity (federal and otherwise) management coordination through iterative communications and consistent protocols would connect separate entities using different approaches. This would additionally consider cumulative impacts, non-linear impacts (the result of two small impacts could be a much larger one), and cross-scale processes.

4. The decision-making method (or combination of approaches depending on the type of decisions and regions) would have the following properties: a) reduces uncertainty, b) anticipates change in a scientific manner, and c) increases the sustainability of the managed SESs to the extent possible while allowing managers to work in a "desirable stage or scenario".

5. Policy and legal issues would be informed by solid scientific knowledge that favors an iterative learning-to-action process without the need to pursue lengthy statutorily updates, which have an average pace that is typically slower than that one of environmental change (e.g., Goerner et al., 2015).

\section{A resilience-based and sustainability-oriented framework}

A general management framework was proposed by Benson and Garmestani (2011a) for DOI and was later generalized by Garmestani and Benson (2013). Later, Kendall et al. (2017) described the pathway followed by scientific and traditional knowledges to inform decisions in BOEM while advocating for a more dynamic framework. In this article, we modify and expand the framework proposed by Garmestani and Benson to incorporate the concept of sustainability and its associated elements, and further provide some insight specific to BOEM. The purpose of the management system presented below is that decisions on offshore resources emanate from a policy-defined framework that is aligned and consistent with the best available knowledge residing in the scientific, indigenous, and environmental management communities. With this in mind, we move forward to first conceptualize the internal structure of BOEM and its processes with outside entities, federal and non-federal. Then we will focus on selecting a specific approach (or group thereof) that would aid decision makers to specify a particular sustainable state that is desired given the information at hand. In this fashion, a decision-informing approach plus the addition of to-be-determined performance elements would be incorporated into the resilience-based initial conceptualization to integrate resilience-thinking and sustainability. The latter is achieved after the system in question meets the a-priori defined performance elements mentioned above. 


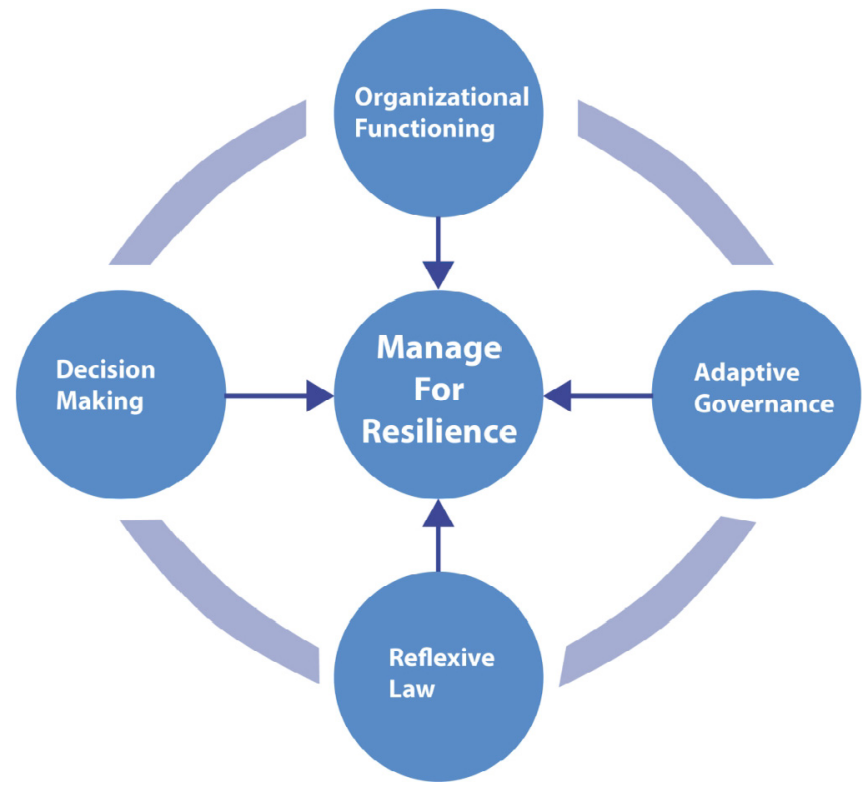

Fig. 3. Fundamental elements of the framework discussed in this article (see Garmestani and Benson, 2013). An overarching management goal at the center is supported by four more specific objectives addressing internal organization (conceptualization), external linkages (adaptive governance), decision-informing approaches (must be iterative), and a legislative and policy framework that provides boundaries.

Based on the challenges summarized in the previous section, it is essential to describe the particular elements of the management framework (Fig. 3) and their coupling in order to understand system function as a whole, and then to identify and navigate the road ahead. While we try to further augment the efficiency and efficacy of BOEM's internal mechanisms, we must keep in mind that an increase in efficiency goes against a basic characteristic of a resilient system, i.e., its diversification in particular and its overall resilience in general. Resilience (which is generally improved by redundancy) and efficiency (which requires reduction of redundancy) oppose each other in the natural world as detailed by Goerner et al. (2015). This issue is addressed by Ulanowicz et al. (2009), who showed that real-world ecosystems maintain a balance between factors contributing to resilience and those contributing to efficiency. Therefore, our intent is to develop a framework that establishes a compromise between resilience and efficiency for operational purposes. Throughout the rest of this paper we will focus on each of the five elements of the proposed work that are illustrated in Fig. 3 while relating them to the specifics of BOEM's structure and function.

\subsection{Internal organization: the panarchy model}

Benson and Garmestani (2011a) proposed an SES for DOI (residing in the former MMS), but their proposed configuration, as described in Garmestani and Benson (2013), did not present a specific organization for the management agency. In what follows, we represent both the ecological and the management aspects through panarchical conceptualizations (Gunderson and Holling, 2002), which include communication between several adaptive cycles operating at different scales. Panarchies have been used to conceptualize different systems, from watersheds and ecosystems to agricultural and energy systems (Dangerman and Schellnhuber, 2013). Graphically depicted in Fig. 4, the panarchy conceptualization builds upon earlier ones, i.e., the adaptive cycle (Holling, 1986) and resilience (Holling, 1973).

In brief, the panarchy model has been widely used to characterize, analyze, and organize different human systems, and to articulate testable hypotheses, e.g., Dangerman and Schellnhuber (2013) used a

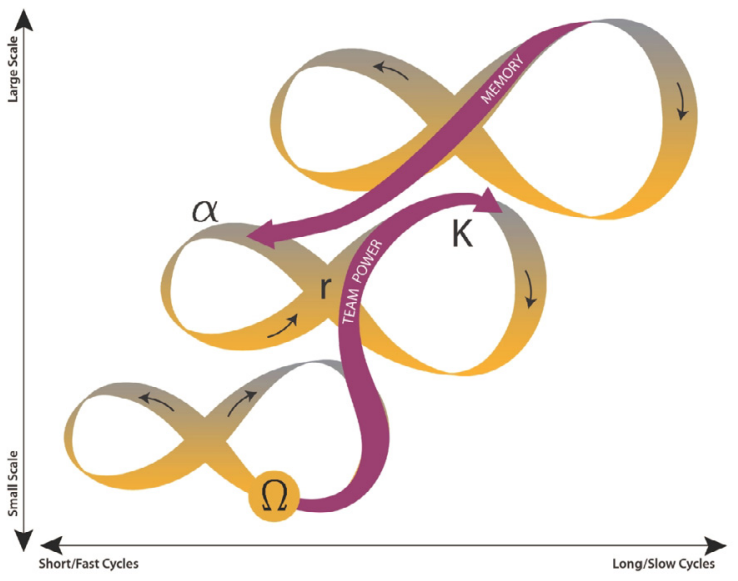

Fig. 4. Panarchy conceptual model as conceived by Gunderson and Holling (2002). It is constructed by connecting different adaptive cycles (Holling, 1986), each associated with a different scale (spatial or temporal).

panarchy conceptualization to analyze the transformation of energy systems, including the oil and gas industry; Warner (2011) applied it to link environmental change to migration; and Gotts (2007) used it as a framework to manage change. Other authors have used it to identify thresholds and opportunities (Groffman et al., 2006; van Apeldoorn et al., 2011), to study how tourism is organized in terms of sustainability (Farrell and Twining-Ward, 2004), and to study the collapse of different systems, including population systems (Kueker and Hall, 2011; Leuteritz and Ekbia, 2008). Most relevant here, Garmestani et al. (2009) assessed the potential of the panarchy theory to be integrated into environmental laws in order for legislative frameworks to provide consistent underpinnings to natural resource management, while others (Garmestani and Benson, 2013; Ruhl, 2012) have proposed major legal reforms in which a dynamic legislation supports managing for resilience while invoking the panarchy model to address socio-ecological considerations. On the other hand, the challenges and opportunities of integrating SESs and law were addressed by Green et al. (2015), and the panarchy model was also used to organize multi-scale agroecosystems (van Apeldoorn et al., 2011). In a single-scale problem, the adaptive cycle was applied to study the historical development of a National Forest in Alaska (Beier et al., 2009). Recently, Kharrazi et al. (2016) presented several advantages of the panarchy approach for addressing resilience issues when compared to the Ecological Information and Statistical Evidence approaches.

Because we address a realistic situation in this article-the management of natural resources by a federal agency-it is important to update and provide more details on the structure of the original adaptive cycle depicted in Fig. 2. Fath et al. (2015) presented a more practical version of the adaptive cycle (Fig. 5), which retains all the key elements of the original version, but is rotated $45^{\circ}$ in a counter-clockwise direction to prevent growth in the reorganization $(\alpha)$ stage, and is also expanded with additional details including possible system behaviors in the $r$ - and K-stages. Note that the growth stage (r) can be characterized by several small wiggles that remain within certain bounds. Smaller adaptive cycles along this stage can also be created and will exist for some time while the overall system continues to develop new internal linkages and increase its resources. A trap (or exit) is noted for the $\alpha$-stage even though these can take place at any of the other three stages when the system exceeds its carrying capacity.

In Fig. 6 below, we first depict a set of connected adaptive cycles that defined the former MMS and how a given event, the 2010 oil spill from the Macondo well in the Gulf of Mexico, led to its replacement by three smaller bureaus/offices: BOEM, the Bureau of Safety and Environmental Enforcement (BSEE), and the Office of Natural Resources 


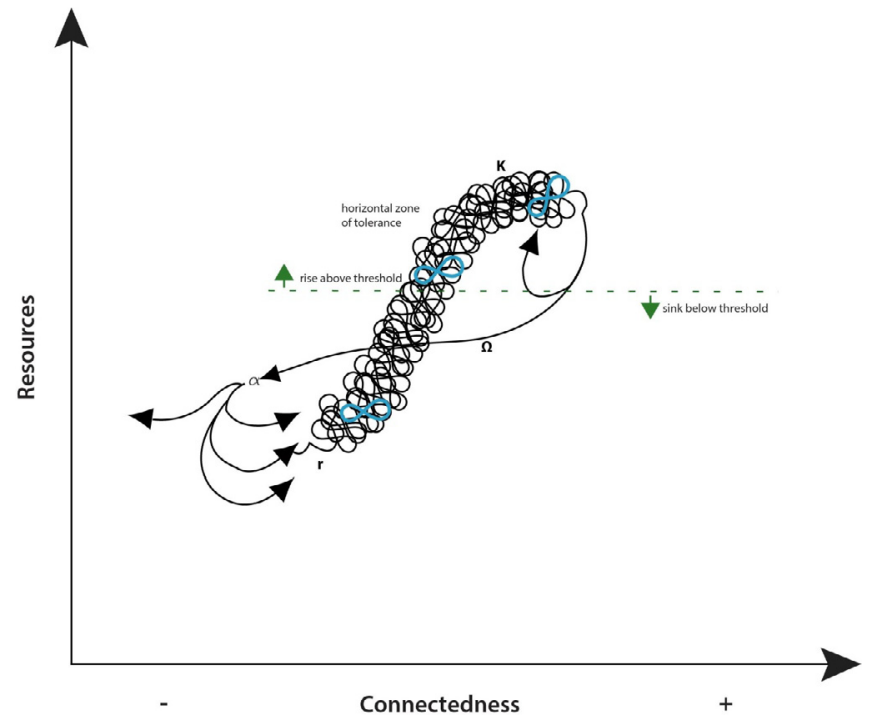

Fig. 5. The adaptive cycle of a system, modified from Fath et al. (2015).

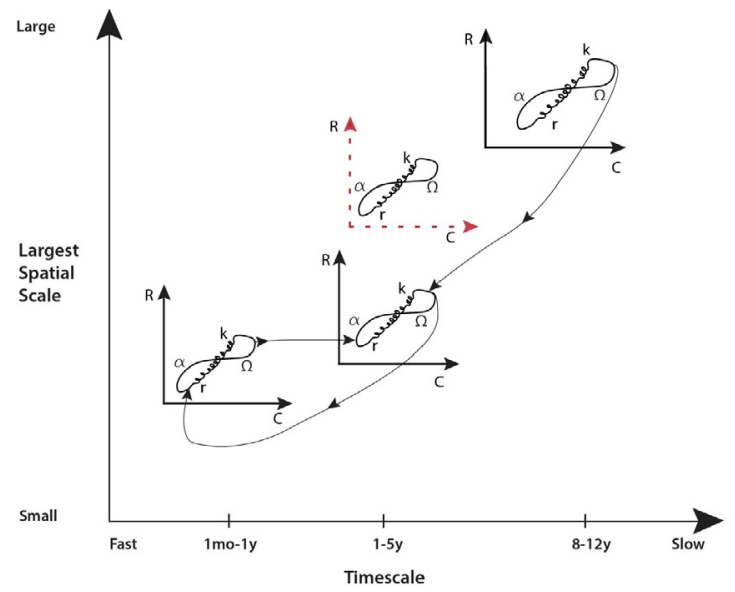

DOI

Fig. 6. A panarchical depiction of DOI (top right) and the former MMS (second cycle from top), which was split into two other bureaus with complementary roles and operating at different spatial and temporal scales. BSEE, at the bottom left, typically focuses on scales that are only slightly larger than those of oil platforms and rigs, while BOEM conducts its operations and studies at those and much larger scales. The arrows connecting the different adaptive cycles corresponding to each agency/department represent different types of communication, from directives and requirements for research to, for instance, data and scientific information or environmental documents. The timescale axis indicates the typical operational cycle, i.e., months for BSEE's monitoring and inspecting and one to five years for BOEM according to their annual funding cycle and their congressionally mandated 5-year cycle. The DOI's high-level policies often fluctuate with an 8-year cycle in response to the alternation of Republican and Democrat administrations. The largest spatial scale corresponds to the scale associated with the bureau's/department's decision making, ranging from blocks $(5 \mathrm{~km})$ to the entire OCS.

Revenue (ONRR). Depicting BOEM and BSEE as functioning with an adaptive cycle that mimics an adaptive ecological cycle is representative of the concept of SES, because that representation a) aids in coupling and synchronizing social and ecological subsystems, and b) depicts their elements with their inherent spatiotemporal scales: programmatic EIS (large), EIS (intermediate), and EA (small), much like in the ecological adaptive cycle. As we will note below, BOEM's functioning is also characterized by a few temporal scales. This holds for other elements as well as their behavior (growth, status quo, release, and reorganization). Overall, the adaptive cycle is suitable for representing BOEM/BSEE, because the relationship over time between resources and connectedness mimics that of an ecological adaptive cycle through those four behaviors. In managerial systems like the one addressed here, the connectedness is chiefly rooted in the quantity and quality of knowledge accumulated and is an indicator of the degree of flexibility of internal variables to external perturbations. The representation of BOEM/BSEE as part of a panarchy facilitates visualizing and thus addressing scale-dependent issues such as connectivity and cumulative effects.

This managerial reduction in scale, which extracted three smaller agencies with respectively distinct missions from one larger one, is equivalent to tectonic shifts in the geological landscape that can isolate previously homogeneous populations, eventually leading to allopatric speciation (Prugh et al., 2008). Not coincidentally, the process that followed the fragmentation of the former MMS was referred to as "reorganization" and corresponded to the $\alpha$-stage of the adaptive cycle shown in Fig. 5. After 2011, this reorganization was followed by a sustained period of growth and refinement (smaller wiggles in Fig. 5), including the development of connectivity between BOEM and BSEE, in order to re-establish some of the connections that had initially been severed by the 2010-2011 split. While the connectivity between functions in the two bureaus are still being developed, it can be considered that BOEM and BSEE are currently functioning in the early part of the $\mathrm{K}$-stage (conservation or status quo phase) and have averted the natural tendency to drift apart.

Fig. 7 zooms in on the smaller (light blue) adaptive cycles seen in the K-stage of the BOEM adaptive cycle in Fig. 5. This smaller cycle represents one that drives the overall functioning of the bureau while it settles into the status quo phase (K-stage), as shown by Benson and Garmestani (2011a, b), and further it can be represented by two nested cycles that have clearly different time scales: a slower one driven by the

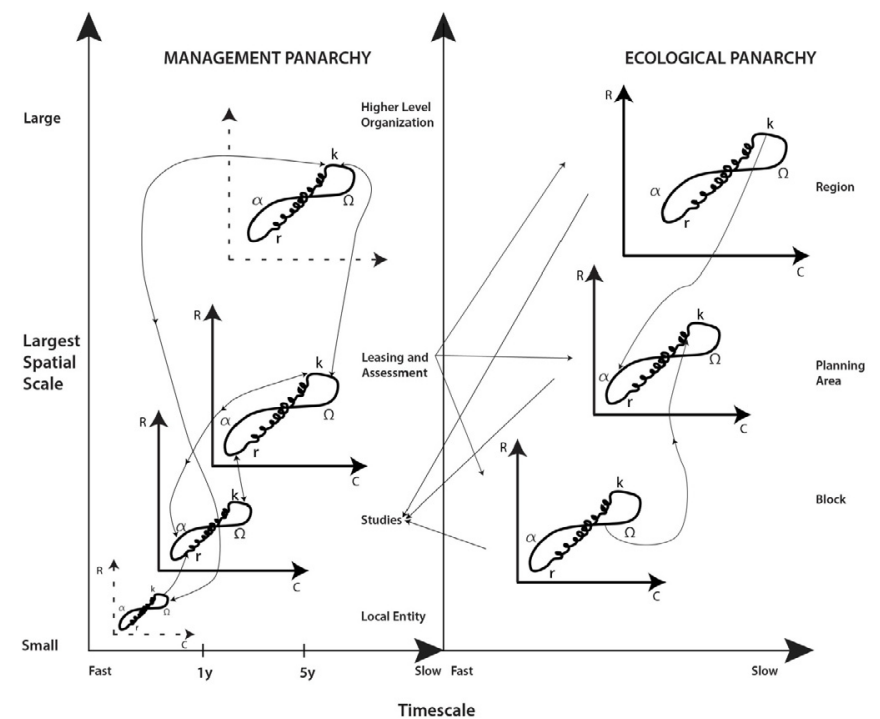

Fig. 7. A Management Panarchy is depicted in the left half, which displays two connected cycles: first the divisions of Leasing and Assessment (which in turn connect to a higher-level cycle, e.g., DOI), and a second one represented by the ESP (research), from which it acquires scientific information to prepare legally mandated environmental documents. At the bottom left, a local entity is included to represent a small-scale organization that regularly provides input to the studies program through consultations. On the right-hand side, the panarchy shown represents the ecological sub-system at different scales: regional (order of $1,000 \mathrm{~s}$ of $\mathrm{km}$ ), planning area (100s of $\mathrm{km}$ ), and block $(1-5 \mathrm{~km})$. The arrows from left to right emanating from the Leasing/Assesment divisions represent decisions made at BOEM, e.g., lease sales. The ESP collects information which flows in the opposite direction, i.e., from the ecosystem panarchy, which includes humans, to the management panarchy. This coupling defines the SES. As it will be illustrated below, this figure represents the social and ecological subsystems of the SES under consideration. 
mandated Five-Year Program's requirements (where assessment and leasing decisions take place), and a faster one that is controlled by an annual funding cycle of environmental research with consideration of information gaps.

Although current linkages between the studies, leasing and assessment cycles are not formal, it was proposed during the time of this writing and earlier (early 2016) that adaptive cycles that facilitate the systematic tracking of information, along and across divisions and levels, are set in place to build institutional resilience. Communicating scientific information up and policy considerations and limitations down is important to reducing uncertainty and to focus research efforts where new findings would inform future decisions. This two-way communication model (Cvitanovic et al., 2015), a form of knowledge co-production, provides a pathway to reducing uncertainty and therefore to more efficient study design, decision making, and overall functioning. It is important to note that, while much progress is needed by the research community in terms of knowledge exchange (Fazey et al., 2013), scientists, analysts, and decision makers also have a role to play (Acheson, 2006; Brown and Farrelly, 2009) in improving current communication structures and in taking practical steps in that direction. Along these lines, Lachapelle et al. (2003) argued that decisionmaking agencies could provide internal flexibility and opportunities to facilitate knowledge exchange among their ranks, while Kettle et al. (2017) argued for the identification of key players, i.e., holders of varied knowledge across disciplines and sectors, who would act to facilitate communication among many. Therefore, communication to the slower-scale cycle (assessment and leasing) from the faster-scale cycle (environmental studies, Fig. 7) is in the form of findings emanating from different projects (publications, reports), while the assessment and leasing divisions also communicate their information needs down to the ESP. This latter path is not a systematic linkage. The communication of knowledge to/from higher levels within BOEM (dashed arrows) has similar properties.

The panarchy on the right hand side of Fig. 7 represents the ecological sub-system under consideration that, for simplicity and as an illustrative example, we represent with three scales often identified in environmental documents: regional scale (large; typically connected to programmatic EISs), planning area (intermediate; typically linked to EISs), and block (smallest; typically addressed by EAs). Although another geographical breakdown could be used depending on the particularities needed by the designer, for this example the order of magnitude of each scale are $1000 \mathrm{~km}, 100 \mathrm{~km}$, and $1 \mathrm{~km}$ respectively. A lease area with a scale of $10 \mathrm{~km}$ could have been added as a fourth scale, but for the sake of simplicity we focus on the three scales noted above. Management of scales below $1 \mathrm{~km}$, like the localized impacts of infrastructure and energy production platforms, are a responsibility that jointly pertain to the environmental enforcement mission of BSEE and BOEM through enviromental monitoring. Impacts at the local scale are important for leasing considerations for BOEM decisions, but the smallest scale considered by BOEM, at least identified in environmental documents, is in the order of $5 \mathrm{~km}$ (block scale) and often smaller when monitoring the vicinity of oil platforms. Smaller scales in the SES connect up to larger ones, e.g., cumulative impacts, while the opposite process (loss of size/scale) can also take place after a crisis or forcing event, e.g., loss of biodiversity (arrows connecting cycles on the righthand side of Fig. 7). Therefore, scientific and traditional knowledges gathered from a given SES are used at one level (environmental studies, lower left cycle) and then assessed and used to inform leasing decisions that could affect that same SES (arrows going from upper left cycle to SES on the right hand side). After we present the other elements of the overall framework, we will provide an example of how to insert an alternative decision-informing approach (with reference to Garmestani and Benson, 2013) more suitable to the case study being addressed in this article.

Zooming in on the faster managerial cycle (lower left cycle), we fit the different elements of BOEM's ESP into the cycle (Fig. 8). For

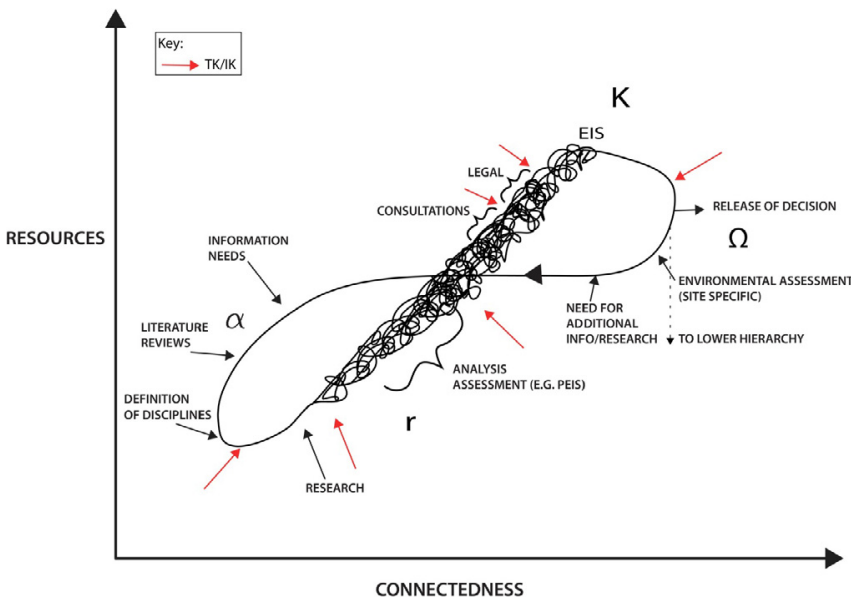

Fig. 8. Fitting of the main elements, that are part of BOEM's internal process, to the adaptive cycle. Each action is associated with the different stages and corresponding properties of the adaptive cycle. In this manner, the evaluation of new information needs throughout the bureau, is part of the reorganization phase ( $\alpha$ ), the data analysis element is associated to the growth phase (r-stage) in resources and connectedness, e.g., information and knowledge, while the conservation phase (K-stage) is linked to a final product that stops growing and is then released to the public ( $\Omega$-stage) as a document and/or decision. The six red arrows represent the six different insertion points where BOEM's regional office in Alaska has successfully incorporated traditional/indigenous knowledge over the last few decades. This knowledge system is discussed along with other elements (black arrows) in Kendall et al. (2017).

instance, the assessment of new information needs, gathered from institutional knowledge, peer-reviewed literature, consultations (see Fig. 8) and reports, belongs in the $\alpha$-stage (the program reorganizes based on what it has learned), then it grows in connectivity by reviewing and refining the original ideas while attracting partners when possible (r-stage), and, finally, it stops when a future research direction is defined and conserved (K-stage) for the remainder of the annual cycle. The prospective research efforts are packaged in a document known as the Studies Development Plan then released (published) with many of the projects being funded based on regional and national priorities ( $\Omega$-stage). The red arrows denote where in this cycle traditional/indigenous knowledge has been used in the past by BOEM's regional office in Alaska (Kendall et al., 2017), although this is potentially applicable to any geographical region.

\subsection{Expanding adaptive governance in BOEM}

Adaptive governance (AG) is a polycentric and decentralized form of governance that brings together different institutions with different and/or complementary jurisdictions over resources belonging to the same SES. Cosens (2010) noted that AG includes legal systems and institutions, as well as collaboration and cooperation at different levels of government and with non-governmental entities. Schultz et al. (2015) noted that AG commonly involves a systematic learning path and reflection of procedures and structures while continuously developing new collaborations toward common goals. Andersson and Ostrom (2008) emphasized the importance of considering natural, socio-economic, and institutional processes from a polycentric perspective that addresses them as well as their linkages. A classical, successful example of AG in the US is the management response to the Florida Bay ecological shift that took place in the 1990s. The coastal ecosystem there shifted from an oligotrophic state to a turbid state dominated by algal blooms in a short period of time (e.g., Groffman et al., 2006; Gunderson and Holling, 2002), which suddenly posed a number of challenges and risks.

AG is a critical element of the proposed framework for 
environmental management because biological processes typically operate through non-linear mechanisms that may create environmental effects on very different spatiotemporal scales and that appear asynchronously from the responsible stressor. The dichotomy of proportional versus second-order interactions is a useful starting point to benchmark efficacy of management strategies because environmental impacts can be reliably anticipated and mitigated by considering one environmental stressor in isolation if the SES responds proportionally, i.e. approximate linearly. However, if the SES has a tendency to respond non-additively to a particular stressor as is common, this suggests that the environmental impact can amplify (or dampen) the SES response due to a variety of other (usually unanticipated) circumstances. Those compounding circumstances may or may not be within the jurisdiction of the governing entity that has to react to the changes in the SES, which highlights the importance of building connections among the environmental missions of governing bodies with contiguous or overlapping jurisdictions.

It is therefore important to consider management decisions with a potential impact on a given SES both a) in isolation and b) together, so their combined impacts, linear or non-linear, are qualitatively and quantitatively considered. Because a key property of SES is their nonlinearity, the possibility of two "small" decisions, each having a negligible effect but jointly imposing significant impacts on the environment cannot be disregarded when multiple decisions are made concurrently or with lasting presence. By addressing the issue of impacts in this manner, it is a way of ensuring that proper consideration is given to both linear and non-linear effects. AG thus is needed in the SES in question in order to consider multiple decisions by different agencies (federal or not) at different scales. In this manner, the harmonized approach proposed by Tamis et al. (2016) could be considered as part of environmental frameworks that manage for resilience.

BOEM has been actively and successfully working in an AG framework for several decades, even though the AG concept was either not well known or non-existent, e.g., Kendall et al. (2017) emphasize the consideration of indigenous knowledge in BOEM's decision making among other elements, such as consultations and partnerships that facilitate coordination and consistency across different organizations, while Eicken et al. (2011) discuss the inclusion of local and indigenous knowledge for environmental mitigation and response in connection to offshore energy development in the Arctic. BOEM annually conducts required consultations with federal, local, state, and tribal governments through a number of coordination bodies, e.g., the National Oceanic and Atmospheric Administration, as well as through engagement with several entities and regional planning bodies on the Atlantic coast. This coordination and collaboration often involves avoidance of offshore energy development in sensitive areas-e.g., highly biologically productive regions and areas where subsistence hunting takes place-while also coordinating research activities at different scales. AG, as a collaborative approach aiming for consistent decisions on natural resource management is thus relatively common in BOEM in particular and the United States in general. Expanding current practices to include consideration of non-linear effects is advocated by the authors as a way to expand and add rigor to current practices.

Therefore, policy elements are needed to shape a dynamic AG structure to more effectively steward SESs (Andersson and Ostrom, 2008) that fall in BOEM's jurisdiction. This would reduce uncertainty for decision makers and establish a more efficient design of research efforts that a) avoid overlapping with other entities, b) facilitate the visualization and understanding of the bigger picture by complementing different research efforts, and c) focus on where the information is truly needed to manage for resilience. Cross-scale management challenges and opportunities are commonly present when dealing with AG frameworks. This needs to be properly addressed and tailored to the specific SES, or adverse outcomes could quickly emerge, as it happened in the case of management decisions on fisheries in the Gulf of California, Mexico (Cudney-Bueno and Basurto, 2009; Reid et al., 2004) when decisions made at the local level negatively impacted fisheries at larger scales.

\subsection{An iterative decision-making approach: aiming for sustainable SESs}

An iterative approach for decision making is needed in order to be aligned with time-dependent characteristics of all SESs and to provide the underpinnings for sustainable management frameworks. This approach would allow managers to work within certain confidence levels, or within certain desired or expected states, which can be set in terms of social and/or ecological preferred states (Chaffin et al., 2016). The framework introduced by Benson and Garmestani (2011a) and generalized by Garmestani and Benson (2013) proposed the adaptive management approach as a decision-informing element that reduces uncertainty in light of new information acquired through monitoring and enhanced knowledge of the system behavior. Adaptive management was used by the former MMS and today by BOEM and BSEE, especially when addressing issues at the smallest scales, such as the management of environmental impacts from a produced water outfall, as studied by Osenberg and Schmitt (1996). However, an issue regarding a variety of other BOEM decisions is that circumstances do not prove conducive to an adaptive management framework when there is very little control over the degree or magnitude of an environmental impact once an activity has been allowed to occur, for it is highly unlikely that structures will be relocated once wind turbines or oil platforms are placed in position. This is why BOEM currently uses site planning to minimize the probabilities of impacts prior to construction, with the exception that some floating platforms can be relocated, although this is very uncommon. Adaptive management is more suitable for situations that allow the managing agency a high degree of flexibility and a high level of control to make decisions that reduce the uncertainty and iteratively tweak the degree or magnitude of impact from the managed activity as needed, e.g., setting fishing quotas or granting hunting permits. Many, but not all, of BOEM's decisions are characterized by low controllability which take place in environments commonly characterized by medium to high uncertainty in terms of ecological and/or social knowledge, a property which points to using an alternative scenario-setting approach capable of adapting to the SES' complexities and time-dependent characteristics. A decision-informing method suitable for low controllability and intermediate to high uncertainty situations, which in turn favors the systematic reduction of uncertainty, is the strategic reframing approach (SRA) detailed in Ramirez and Wilkinson (2016), which is discussed below.

In BOEM's particular case, it is important to consider a number of variables in order to start the process of scenario setting and iteration to reframe the decision over time. Several domestic and international factors often affect national policies on energy and its development. Given the need to address environmental laws and regulations, any strategic reframing must also consider environmental (e.g., climate scenarios) and economic issues (e.g., the price of a barrel of oil). The Intergovernmental Panel on Climate Change (IPCC) report (Barros et al., 2014) and the North Slope Science Initiative Scenarios report (Vargas-Moreno et al., 2016) are two recent examples, respectively. Therefore, an SRA would require a comprehensive and integrative approach of key socio-ecological variables needed by BOEM, as well as a realistic schedule that can be updated to capture changes in timescales relevant to potentially upcoming decisions.

Strategists under the umbrella of the SRA become "learners," as noted by Ramirez and Wilkinson (2016), who ideally must re-perceive and reframe with increased efficiency over time, as their updated perspectives are broadened with newly acquired knowledge. It is worth noting here, that the SRA also constitutes a powerful approach for conflict resolution when multiple stakeholders are present with varied perspectives, something that could arise when applying the seven principles listed in the first section. In BOEM's particular case as a natural resources management agency, an SRA would need to consider 


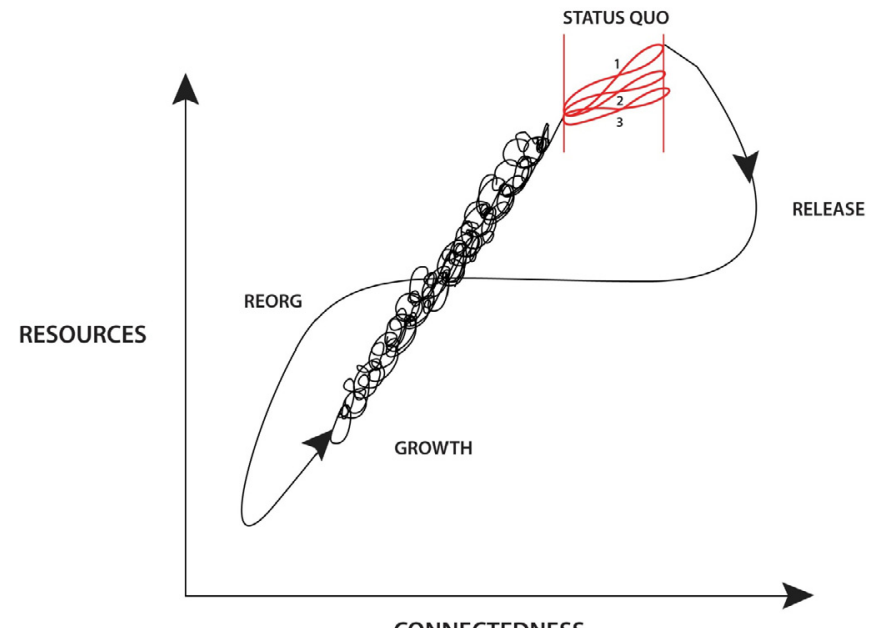

CONNECTEDNESS

Fig. 9. In this paper, the authors have modified the Fath et al. (2015) adaptive cycle by replacing an inner adaptive cycle on the K-stage of the larger cycle (see Fig. 5) with a number of prescribed adaptive cycles (red) that are set through a scenario-setting exercise and that are iteratively developed through a strategic reframing approach which would be updated as contextual and transactional elements significantly change over time.

all factors involved (institutional, socioeconomic, and ecological) and potentially affected by offshore energy development on the OCS in order to efficiently design research efforts that will inform its decisionmaking process. Researching into any given SES scenario, will be faciliated by identifying SESs' states and their proximity to key thresholds, especially in light of current warming trends and other regional and global drivers. Therefore, alternative SES scenarios will differ in terms of the risks and their associated potential impacts on the SES under consideration, which selection could consequently influence how future research investments would be allocated to inform decisions. Fig. 9 shows three operational scenarios in the K-stage of the BOEM adaptive cycle, among which decision makers can switch every time that the current strategy is reframed, or alternatively, consider elements common to more than one scenario.

\subsection{Enhancing resilience in the adaptive cycle: the US Outer Continental Shelf}

Establishing a management goal for a research program, such as managing for resilience, has several advantages, and this has been highlighted by Benson and Garmestani (2011b) who listed the resilience-based management objectives of the US Forest Service, the National Marine Fisheries Service of the National Oceanic and Atmospheric Administration, the US Fish and Wildlife Service, and the US Bureau of Reclamation. The last two agencies, like BOEM, are part of DOI. In BOEM's specific case, this goal would allow, among other advantages, for different research studies to be systematically connected horizontally (with other concurrent studies) and vertically (with past studies). In this manner, each study represents one piece of a puzzle that would help visualize the bigger picture defined by a significant portion, or the totality, of the SES under consideration.

Central to the preservation of natural resources through a resiliencebased approach is the identification of system states and how close they are to critical environmental thresholds, e.g., shifts from an oceanic benthic-dominated state to a pelagic-dominated state, or as in the Florida Bay example noted above, transitioning from an oligotrophic state to a turbid one in a short period of time. There are several examples of methods in the literature for identifying thresholds, especially in connection with the adaptive cycle conceptualization and resiliencethinking. Mumby et al. (2007) addressed the resilience of Caribbean reefs by looking at the thresholds in the space defined by the coral cover-grazing pair and studying how hurricanes could potentially favor a threshold crossing. Using paleo data, Willis et al. (2010) addressed how climate processes responsible for setting thresholds can be considered when addressing conservation and natural resource management. To add specificity to these topics, Carpenter et al. (2013) presented a new approach for the detection of thresholds in ecosystems in connection with resilience considerations, while Rockstrom et al. (2009) identified planetary boundaries that must not be transgressed to prevent human activities from causing unacceptable environmental change. More recently, resilience thresholds have been invoked to study marshes impacted by oil spills (Silliman et al., 2016), to better understand the spatial resilience of SES (Cumming et al., 2017), to improve fisheries management (Craig, 2017), and to integrate important elements of natural resource management, such as SES resilience (Farley and Voinov, 2016).

Research agendas would then need to consider every action associated to each resilience principle listed above. That consideration would also involve the a priori identification and quantification of system resilience, especially diversity, connectivity, and redundancy through the construction of detailed ecosystem maps. Flexibility is a fourth resilience property that we discussed above. It can be more difficult to quantify, although there are several studies that consider resilience with flexibility as a particular focus, such as rapidly changing conditions in the Arctic region where change is happening two to three times faster than elsewhere. There, flexibility is reflected in the shifting diets of indigenous peoples (Mead et al., 2010), seals (Yurkowski et al., 2016), and polar bears (Gormezano and Rockwell, 2013). The construction of these ecosystem maps points to the task of ecosystem assessment and monitoring as an integral component of programs and/or entities managing for resilience. In the adaptive cycle, this aspect belongs in the $\alpha$-stage (reorganization) where new information is acquired to establish information gaps and needs, reframe strategies, and focus research efforts in such a way that the connectivity of the system increases along with resources (Fig. 8). Quantifying these four variables would certainly facilitate the construction of practically useful resilience indexes as has been done for climate disasters (Joerin et al., 2014), for measuring economic resilience (Briguglio et al., 2006), and for quantifying flood resilience based on socio-ecological variables (Kotzee and Reyers, 2016).

\subsection{Legal and policy considerations}

Continuous learning and adaptive processes characterize the framework proposed here, as well as each of its elements separately. For the sake of consistency, law and policy should both provide a favorable background that resonates with the managerial, governmental, and organizational concepts defining the overall working environment. In this manner, any decision making that emanates from this framework would likely be effective given that its elements and goals are aligned toward reducing uncertainty for decision makers. To achieve this, Craig and Ruhl (2014) described a proposed Model Adaptive Management Procedure Act (MAMPA) in which a particular decision-informing approach is at the core of legislation. Although BOEM does occasionally use adaptive management, their proposed legislation could be generalized to also include other appropriate iterative decision-informing approaches, such as strategic reframing. Therefore, when and if such legislation is enacted, it could reach a larger number of agencies across the federal family, not just those whose missions tend to attract the use of adaptive management. Craig and Ruhl's (2014) advocacy for consistent legislation that includes the definition of an overarching management goal, such as the MAMPA, adds to previous efforts since these arguments have been invoked in one form or another by legal scholars since the early 1990s. For example, Orts (1994) discussed the need for flexibility and legal consistency in the management of natural resources that reflexive laws could provide. In the mid to late 2000s, Karkkainen (2005), Garmestani et al. (2009), Benson and Garmestani (2011a), Ruhl 
(2012), Garmestani et al. (2013), and Craig and Ruhl (2014) proposed other legal reforms to improve management of natural resources. This legal discourse attempts to address the existing disconnect between current (linear and static) laws and panarchical organizations (dynamic, non-linear), and raises the concern about the ability of these organizations to achieve their stated goals and objectives in a manner that is fundamentally consistent with the best available (scientific and traditional) knowledge. In lieu of legislative reform, it is possible that BOEM, and even DOI as a whole, could pursue the proposed dynamic framework for environmental management, considering systematic and self-learning adaptive-like cycles, in its elements and procedures, provided that the overall framework and approaches are consistent with departmental authority and current legislation.

\section{Two practical tests}

The proposed framework can be used both to generate testable hypotheses and to aid managers in making more defensible decisions. Two realistic, although speculative, situations are discussed next, addressing initiatives for introducing a specific modification to BOEM's organizational structure and its processes. In the first case, the ecosystem services approach is proposed as a minor modification to existing practices for developing analyses to support bureau decisions. In the second case (major modification), BOEM is merged with its sister bureau, BSEE. These practical examples are given to test and illustrate the inner workings of the proposed framework.

\subsection{Test case 1: introducing the ecosystem services (ES) approach}

The ES approach provides a way for managers and stakeholders to value different monetary benefits provided by nature in order to inform different decisions for a given SES. We first consider that one possible insertion point for the ES concept is in the prioritization of proposed studies that are considered annually by BOEM's ESP. Because these studies will emanate from a specific high-level mandate to address a particular SES aspect and/or from the overarching goal of managing for resilience, the ES approach can be introduced as an additional layer of granularity to assign different values to the different proposed studies based on their scopes, budgets, and duration in light of managerial schedules, values, and stakeholder input. We then focus on Fig. 8, where we identify the section of the cycle where studies are generated and further verify that the ES approach fits with the functionality of the reorganization stage. The introduced novelty (a new element/process) in this framework in general, and in one of the adaptive cycles in particular, does not lead to a systemic shift in the overall cycle and associated processes; rather, the $\alpha$-stage absorbs this new element in its regular reorganization stage without leading to either systemic change in structure or further a change in scale (Allen et al., 2014). Therefore, having a framework in place, such as the one defined here, makes the decision of adding the ES approach to the overall process a more defensible one. If the decision maker had introduced the ES approach in another stage of the overall annual cycle, then it could have led to a destructive outcome depending on a number of factors that involve comparing the properties and nature of the new action or element, to the different properties of each stage of the adaptive cycle in which the insertion would take place. This knowledge is also relevant to prepare managers and actors for upcoming stages in the adaptive cycle, which would better inform decision makers and therefore improve organizational preparedness and overall resilience. However, we wish to note that the introduction of a given element, in this example the ES approach, could be achieved in different ways and therefore, depending on the specific implementation details, the new component could be successfully added at different insertion points of the overall cycle. It is worth mentioning that certain elements could produce positive outcomes regardless of the insertion point. Kendall et al. (2017) showed that the introduction of traditional/indigenous knowledge at six different insertion points enhanced the overall process (Fig. 8), although they noted that its early introduction in the process is ideal most of the time. An introduction with a positive effect on an internal process/cycle could be the arrival of a new process, just as the introduction of non-native species could have positive effects on alpha diversity and increase resilience (Allen et al., 1999, 2014; Forys and Allen, 2002). It is worth mentioning that ES-based approaches would need to be consolidated in conjunction with a solid resilience-based approach, such as the one addressed in this paper, to prevent undesirable outcomes as noted by Ruhl and Stuart Chapin (2013) and more specifically by Laterra et al. (2016). After this consideration for resilience, an ecosystem-based approach can be safely designed as recently shown by Elliff and Kikuchi (2015).

\subsection{Test case 2: merging BOEM and BSEE back together}

In 2010, the former MMS was split into ONRR and the Bureau of Ocean Energy Management, Regulation, and Enforcement (BOEMRE). The latter was then split into the current BOEM and BSEE in 2011, all in response to high-level directives following the 2010 oil spill in the Gulf of Mexico. Fig. 6 displays the pre- and post-split cycles associated with the former MMS and the current BOEM and BSEE. The split in question involved a change in scale from the large MMS to three smaller organizations. Although this involved both, a loss of connectivity among previously linked processes, and the usage of resources to support three reorganization processes, the memory residing in the current panarchy in Fig. 6 could be used in a potential merger, part of a larger DOI reorganization or not, to make the process more efficient.

In this test we only address the environmental aspect of a broader set of management issues relating to BOEM and BSEE's jurisdiction. To analyze this potential merger, we thus focus on the current linkages between them. First, BSEE operates on timescales that are similar to, or faster than, BOEM's as shown in Fig. 6. BSEE's funding of different studies also has an annual cycle like BOEM's, but BSEE's monitoring activities take place on much faster (smaller) temporal (spatial) scales, as its focus is typically associated to safety issues at the location of oil platforms (site specific). Second, after a leasing decision by BOEM and the beginning of the exploratory and development phases, BSEE begins its monitoring and inspection activities duties. As needed, BSEE communicates back to BOEM with recommendations for additional environmental information. This latter communication cycles back to BOEM and could therefore be made more efficient by incorporating all of its elements into one consolidated process/cycle that addresses the needs for information in an integrated manner. Therefore, fusing the two bureaus would institutionalize systematic adaptive-like cycles, e.g., similar to those needed among divisions, to facilitate two-way transfers of knowledge and, following Goerner et al. (2015), it would increase efficiency by increasing streamlining and initially decreasing resilience by decreasing flexibility. The newly created bureau could now be represented by a new organizational panarchy covering several geographic and temporal scales and eliminate the need for AG between both bureaus as well as that one of any bridging organizations in delivering consistency and efficiency in natural resource management. In this test case, any bridging and cooperation between the bureaus, e.g., through agreements, are replaced by their integration into a larger and more efficient cycle, including the coordination of monitoring activities previously conducted separately and at different scales. Specifically, the integration of small (BSEE) and larger (BOEM) scales monitoring activities into a single organization would also greatly facilitate the implementation of possible adaptive management efforts in line with current practices in DOI (Williams and Brown, 2012).

This potential integration of both bureaus is fundamentally important for effectively addressing cross-scale issues that could lead to environmental impacts associated with mismanagement of cross-scale issues, e.g., Cudney-Bueno and Basurto (2009). It would also be empowered by having one decision agency overseeing all monitoring and 


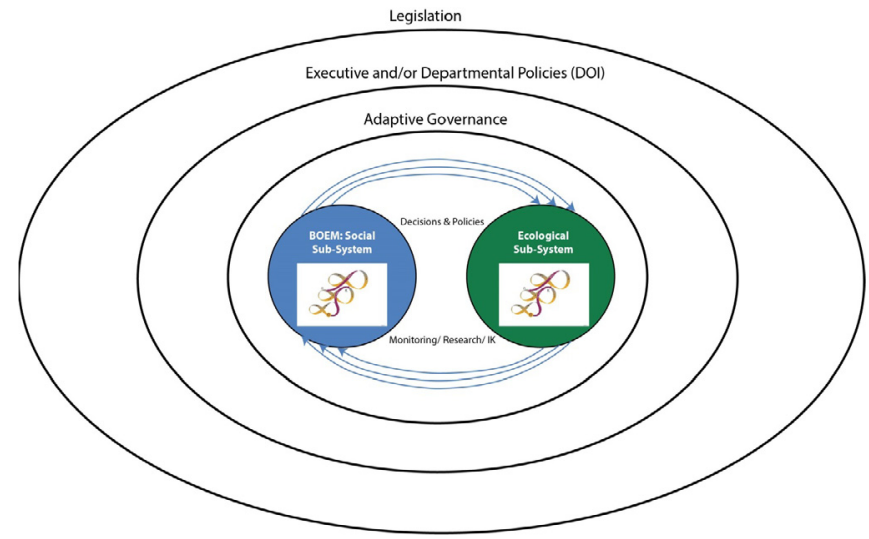

Fig. 10. Summary characteristics of the BOEM framework developed for SES stewardship. The internal organization of BOEM (social sub-system), and the ecological sub-system both include humans, are each represented by a panarchy. Each triplet of arrows connecting BOEM and ecosystem panarchies represents three different a priori selected scenarios that support the sustainability of the SES. The connectivity of both sub-systems (panarchies) is defined by decisions informed by strategic reframing on monitoring, research, and indigenous knowledge. The different levels represented as large ovals are elements, e.g., adaptive governance, that provide contextual and transactional information to everything within them. The three scenarios, for instance, are influenced by adaptive governance, executive and departmental policies and existing legislation. Modified and adapted from Green et al. (2015).

planning activities, rather than the present situation in which there are managers and decision-makers in BOEM (intermediate and larger scales) and in BSEE (smaller scales). Another benefit that is not readily obvious is that integrating both agencies' processes into one systematic and coordinated adaptive cycle will reduce the probability of having cumulative impacts by which processes at a given scale negatively impact a larger one. This benefit is critical as the smaller scales that are associated with the size of different structures (e.g., oil platforms) will tend to be impacted first and then cascade up to larger scales, e.g., as in the case of produced waters studied by Osenberg and Schmitt (1996). Therefore, the connection to the larger scales which BOEM often considers could be improved through consolidation of BOEM and BSEE management authority. The argument for this consolidation is illustrative of the higher levels of cooperation that are possible through this dynamic framework for environmental management. Fig. 10 summarizes described concepts, processes, and architectures, and it also illustrates the important role of monitoring in influencing decisions and policies. Scale discrimination, cross-scale processes, and other related issues are critically important to consider with this merger. These issues are conceptually addressed by the panarchical representation and used implicitly here to discuss this potential merger.

\section{Discussion}

We have presented a dynamic framework that can be used by BOEM for stewardship of SESs potentially affected by offshore energy exploration and development, as well as marine minerals extraction.. It aligned a) internal organizational elements, b) decision-informing approaches, c) governance, as well as d) legal and policy considerations, all consistent with an overarching goal of managing for resilience. There is consensus in the environmental management science community that several elements must be considered in order to implement an effective resilience-based management framework, while more specific implementation recommendations may be further considered for each of those components.

In order to implement this framework, BOEM may have to re-envisionits internal organization by including systematic, policy-supported cycles that also ensure the systematic two-way tracking of information among scientists and decision makers at all levels. This joint identification of information needs would have to consider and balance a number of elements, including socio-ecological studies that need to address specific legal mandates and the overall goal of managing for resilience. BOEM could also start conducting specific resilienceoriented assessments for each region (Gulf of Mexico, Alaska, Pacific, and Atlantic), and gather fundamental information such as identification of thresholds and conditions that could lead to the loss of resilience, or more practically, to shifts in ecosystem states (threshold crossing). This assessment will also point to information gaps that would be tackled in subsequent funding cycles. Specifically, this would include studies that focus on the driver-response of the SESs stewarded by BOEM to reduce uncertainty and to focus research efforts in areas that closely relate to the potential for negative impacts. Such studies have produced results and findings useful to inform management decisions in diverse environmental areas such as driver-response relationships in marine ecosystems (Hunsicker et al., 2016), human-environment feedbacks (Scott and Buechler, 2013), and diversity of responses of a given SES in connection with its resilience (Mori et al., 2013). Further, explicit connection of studies both horizontally (simultaneous in time) and vertically (historically) could facilitate the construction and visualization of a larger picture: ecosystem structure and function in the context of an SES, including integrative studies that assess first- and second-order effects of management actions. This reenvisioning could be motivated through the definition of a number of key performance elements, not only to provide transparency, to track progress and correct any necessary issue, but also to enhance the learning by all, which is at the core of knowledge co-production. The overall desired outcome is to produce better returns on research investment, e.g., ensuring that limited research funding is invested on research efforts on system elements that are potentially vulnerable.

Decision-making supported by this framework involves iterative scenarios that factor in different contextual and transactional considerations that are both internal and external to BOEM. To some extent, some of these would be influenced by changing socio-ecological conditions in different geographical areas, and therefore different scenarios would need to be considered in the planning process of the different regional offices of BOEM. Ecological and sociological factors would need to be aligned to present scenarios that would inform the overall planning process. The update frequency of those scenarios would need to consider the current pace of environmental change as well as internal and external requirements, such as the mandated FiveYear Program. Therefore, the latter timescale (5 years) would be reasonable for updating the scenarios which define the SRA. This timescale would also influence the schedule of any long-term monitoring efforts, which are a needed element in the reorganization stage of an adaptive cycle. The anticipatory character of the strategic reframing decisioninforming approach would provide a way to reduce the vulnerability, and therefore enhance the adaptive capacity of SESs to changes in environmental conditions, high-level policies, and/or politico-economic scenarios.

Adaptive governance addresses the existing (mandated or not) external linkages with other federal, state, local, and tribal organizations that are needed to maintain the historically good record of consistent decisions across geographical scales. BOEM could also add a sciencebased consideration of the potential non-linear impacts of multiple decisions made in a given SES, regardless of whether those decisions are sequential or simultaneous. While there is a growing use and application of SES frameworks, several of them referenced in this article, it is relevant to note that the SES conceptualization has some limitations as well, especially when considering interpretative traditions of social research (Stojanovic et al., 2016). However, progress has recently been made by Thompson (2017) who has adapted the Holling cycle into his work on cultural theory, while a resolution of this issue would emphasize the "social" component of the SES, e.g., as described by Fabinyi et al. (2014). 
Legal and policy considerations are the final component of the framework. Garmestani et al. (2013) notes that legislative reform is due in the US, especially because the current knowledge on the functioning and management of SES has grown and evolved on all fronts over the last 50 years, the period after many of the current environmental laws were written and passed. However, there are options within the proposed framework for environmental management that are consistent with existing legislative authority. It is perhaps necessary to consider all options on the table, such as looking for governance opportunities at all reachable levels and sectors. The Council on Environmental Quality (CEQ) could act within its authority under existing laws to re-interpret the concept of "harmony" mentioned in the NEPA. This intermediatelevel action would update current definitions and interpretations on system state and dynamics to more realistic and well-established terminology. Specifically, harmony could be defined as the ability of a given system to successfully remain on the path of an adaptive cycle (as defined by Fath et al., 2015) while maintaining structure and function, or it could be defined in another manner that is consistent with today's understanding and knowledge of SES dynamics. A specific example that illustrates the need for a legal revision to support the management for resilience deals with environmental sensitivities as the OCS Land Act requires BOEM to address "relative environmental sensitivity." However, a problem with the focus on sensitivity is that real systems can exhibit several basins of attraction with highly non-linear behaviors, a trademark of the complex SESs discussed here. It is certainly possible that a given system exhibits significant sensitivities to a particular stressor while it is in a state that is far away from crossing dangerous thresholds, i.e., in a resilient state. The opposite is also true, i.e., a small response (low sensitivity) by the system could lead to a threshold-crossing situation, thus leading to a loss of resilience and significant environmental impacts. Therefore, sensitivity is simply not an informative benchmark of system performance on its own, absent some sort of evidence for continued system resilience.

Therefore, the integration of all the modular elements discussed thus far (Fig. 10) involves selecting desired outcomes and/or behaviors, through strategic reframing, that will support a sustainable, selflearning, and flexible managerial and governmental approach, as well as the desired, mission-guided outcome of reducing or avoiding environmental impacts. These relate to all exploration and development of offshore energy-conventional or renewable-as well as to the extraction of marine minerals from the OCS. In this manner, agency efforts are geared toward sustainable operations over time (K-stage in Fig. 9) by following an SRA, with annual and pentadal cycles involving successful navigation of all phases ( $r, \mathrm{~K}, \Omega$, and $\alpha$ ) of the smaller adaptive cycles (division-level functioning) shown in Fig. 7 and detailed in Fig. 8. This will favor the bureau's continuous presence in the above mentioned sustainable (K) stage of the adaptive cycle shown in Fig. 9. A case could be made about the long-term sustainability of offshore energy resources and BOEM's need to manage them. Unlimited resources such as wind, waves, and ocean currents can be used to provide sustainable energy to societies. Therefore, as the need for renewable energy grows, there must be a corresponding growth in management needs which would require a (slow) transition within the K-stage of the corresponding agencies. To ensure this operational sustainability, the SRA would ideally consider SES scenarios involving all relevant elements in the domestic and global scales.

Following the navigational recipes presented by Fath et al. (2015), it is important to anticipate and prepare for unexpected circumstances in order to increase the strength and resilience of the adaptive cycles in question. These a priori organizational investments and arrangements would not only make the navigation through the different phases of the adaptive cycle successful, but would also reduce the risk of falling into one of the four different traps (loss of resilience) the authors identified. In practical terms, this could occur when the system in question is unable to halt negative feedbacks (r-stage) that have taken it beyond its carrying capacity. Falling into these traps is equivalent to crossing a threshold; therefore, it is important to identify them, their location in phase space, and their distance to different system states. It is therefore important to identify the rules and mechanisms by which the SES behaves and responds to different situations. One such proposition is that management entities can only influence the adaptive cycles in which they operate. Selection is an important mechanism for change, which may be made by a management entity in anticipation of different system dynamics within the boundaries of pre-selected scenarios that aim for a sustainable structure and functioning of the SES in question. It may be then prudent to begin considering the task of selecting against scenarios, e.g., one consideration could include selecting against undesirable dynamics, such as vulnerability. There is already precedent in the environmental management community-the precautionary principle-which is justified on legal and ethical grounds. However, under this framework, agency selection would additionally need to consider knowledge on the SESs' structure and function.

\section{Conclusions}

Although BOEM has been using some aspects of the proposed socioecological, resilience framework, this paper encourages formalization of those practices, while adding new elements. This includes integration of its elements and overall implementation through dynamic policies consistent with the spirit of the framework, i.e., a management and governance system in sync with the dynamics of the managed SES. Its social sub-system would include cooperative behavior, within the entity in question and with external entities, such as consultations (mandated or not) and the consideration of non-linear impacts of multiple actions of different regulating organizations. We further suggest that both strategic reframing and adaptive management be jointly considered as separate and iterative decision-informing methods to deal with small and large-scale issues, respectively. The former is appropriate given the low controllability of SES elements that characterizes most aspects of BOEM's mission and corresponding decisions. Annual and pentadal cycles that were identified in the bureau's internal working also served to identify key inter-division connectivities. One advantage of the framework discussed in this article is its modularity, in the sense that several aspects could be incrementally adopted if desired, and further, that implementation could be carried out in parallel or sequentially at the discretion of the decision makers. This modularity and flexibility further applies to regional implementation across the bureau's different regional offices, including its national office. The overarching management goal, supported by dynamic policies and reflexive legislation, will contribute to resilient and therefore more sustainable practices and SESs. They will also result in more effective investments and utilization of all resources, reduction of uncertainty, and increased defensibility of future policies and decisions.

In this article we have purposely avoided discussing specific implementation details of the framework which are being considered for a follow up article. However, the authors believe that they have approached implementation in more depth than in other studies found in the literature, in the sense that the analysis and discussions presented here are focused on a specific organization. The hope is that this analysis provides a first step towards a practical implementation by BOEM of the framework presented in this paper. Nothing prevents this framework from being adapted and used by other organizations (gubernamental or not) charged with natural resource management duties, or as shown recently by Auad (2017) to coordinate and align different organizations with complementary missions in the state of Alaska, as they address a number of socio-ecological challenges and opportunities presented by climate change.

\section{Funding}

This work was supported by the Bureau of Ocean Energy Management. 


\section{Acknowledgments}

I (GA) am indebted to Abigail Ross Hopper for her vision and encouragement for us to develop an efficient management framework for BOEM. My appreciation also goes to Joel Clement who enthusiastically encouraged me to move ahead with a resilience-based approach. I am especially grateful to Jim Kendall for his encouragement to publish the results of the present work. We thank Hajo Eicken, Walter Cruickshank, William Brown, Rodney Cluck, Walter Johnson and Amardeep Dhanju for their many suggestions that greatly contributed to enhance the readability and quality of this article. We thank Ashley Scutari and James Bennett for their professionalism in preparing the figures shown in this paper, and Paulina Chen for her careful technical editing of this manuscript. We thank BOEM for their support of GA, JB and KC to work on the development of the framework described here, and in the preparation of this article. The comments and suggestions of an anonymous reviewer greatly contributed to improve the quality of this paper. The views expressed herein are solely those of the authors and do not necessarily represent those of the United States Government, the US Department of the Interior, or the Bureau of Ocean Energy Management.

\section{References}

Acheson, J.M., 2006. Institutional failure in resource management. Annu. Rev. Anthropol. 35, 117-134.

Allen, C.R., Angeler, D.G., Garmestani, A.S., Gunderson, L.H., Holling, C.S., 2014. Panarchy: theory and application. Ecosystems 17, 578-589.

Allen, C.R., Forys, E.A., Holling, C.S., 1999. Body mass patterns predict invasions and extinctions in transforming landscapes. Ecosystems 2, 114-121.

Anderies, J.M., Folke, C., Walker, B., Ostrom, E., 2013. Aligning key concepts for global change policy: robustness, resilience, and sustainability. Ecol. Soc. 18.

Andersson, K.P., Ostrom, E., 2008. Analyzing decentralized resource regimes from a polycentric perspective. Pol. Sci. 41, 71-93.

Auad, G., 2017. From Executive Desks to the Arctic Ocean and Back: a Dynamic Framework for Natural Resource Management. AGU Fall Meeting. American Geophysical Union, New Orleans, Lousianna, USA.

Ball, P., 2017. Decoding deep similarities. Nature 545, 155-156.

Barros, V.R., Field, C.B., Dokke, D.J., Mastrandrea, M.D., Mach, K.J., Bilir, T.E., Chatterjee, M., Ebi, K.L., Estrada, Y.O., Genova, R.C., Girma, B., 2014. Climate Change 2014: Impacts, Adaptation, and Vulnerability. Part B: Regional Aspectscontribution of Working Group II to the Fifth Assessment Report of the Intergovernmental Panel on Climate Change. Cambridge University Press, New York, USA.

Beier, C.M., Lovecraft, A.L., Chapin, F.S., 2009. Growth and collapse of a resource system: an adaptive cycle of change in public lands governance and forest management in Alaska. Ecol. Soc. 14.

Benson, M.H., Craig, R.K., 2014. The end of sustainability. Soc. Nat. Resour. 27, 777-782.

Benson, M.H., Garmestani, A.S., 2011a. Can we Manage for resilience? The integration of resilience thinking into natural resource management in the United States. Environ. Manag. 48, 392-399.

Benson, M.H., Garmestani, A.S., 2011b. Embracing panarchy, building resilience and integrating adaptive management through a rebirth of the national environmental policy act. J. Environ. Manag. 92, 1420-1427.

Berkes, F., 2009. Evolution of co-management: role of knowledge generation, bridging organizations and social learning. J. Environ. Manag. 90, 1692-1702.

Berkes, F., Folke, C., Colding, J., 2000. Linking Sociological and Ecological Systems: Management Practices and Social Mechanisms for Building Resilience. Cambridge University Press, New York, USA.

Biggs, R., Schluter, M., Biggs, D., Bohensky, E.L., BurnSilver, S., Cundill, G., Dakos, V., Daw, T.M., Evans, L.S., Kotschy, K., Leitch, A.M., Meek, C., Quinlan, A., Raudsepp Hearne, C., Robards, M.D., Schoon, M.L., Schultz, L., West, P.C., 2012. Toward principles for enhancing the resilience of ecosystem services. Annu. Rev. Environ. Resour. 37, 421-448.

Briguglio, L., Cordina, G., Farrugia, N., Vella, S., 2006. Conceptualizing and Measuring Economic Resilience. Building the Economic Resilience of Small States, Malta: Islands and Small States. Institute of the University of Malta and London, Commonwealth Secretariat, Malta.

Brown, R.R., Farrelly, M.A., 2009. Delivering sustainable urban water management: a review of the hurdles we face. Water Sci. Technol. 59, 839-846.

BOEM, 2012. Traditional Knowledge and the National Environmental Policy Act Process at BOEM, Ocean Science. United States Department of the Interior, Washington, D.C pp. 11-11.

Carpenter, S.R., Brock, W.A., Cole, J.J., Pace, M.L., 2013. A new approach for rapid detection of nearby thresholds in ecosystem time series. Oikos 123, 290-297.

Chaffin, B.C., Garmestani, A.S., Angeler, D.G., Herrmann, D.L., Stow, C.A., Nystrom, M., Sendzimir, J., Hopton, M.E., Kolasa, J., Allen, C.R., 2016. Biological invasions, ecological resilience and adaptive governance. J. Environ. Manag. 183, 399-407.
Cosens, B., 2010. Transboundary river governance in the face of uncertainty: resilience theory and the Columbia river treaty. J. Land Resour. Environ. Law 30, 229-265.

Council, A., 2016. Arctic resilience report. In: Carson, M., Peterson, G. (Eds.), Stockholm Environment Institute and Stockholm Resilience Centre, Stockholm, Sweden, pp. $1-218$.

Craig, R.K., 2013. Learning to think about complex environmental systems in environmental and natural resource law and legal scholarship: a twenty-year retrospective. Fordham Envinron. Law Rev. 24, 87-102.

Craig, R.K., 2017. Putting resilience theory into practice: the example of fisheries management. Nat. Resour. Environ. 31, 5.

Craig, R.K., Ruhl, J.B., 2014. Designing administrative law for adaptive management. Vanderbilt Law Rev. 67, 1-87.

Cudney-Bueno, R., Basurto, X., 2009. Lack of cross-scale linkages reduces robustness of community-based fisheries management. PLoS One 4.

Cumming, G.S., Morrison, T.H., Hughes, T.P., 2017. New directions for understanding the spatial resilience of social-ecological systems. Ecosystems 20, 649-664.

Cvitanovic, C., Hobday, A.J., van Kerkhoff, L., Wilson, S.K., Dobbs, K., Marshall, N.A., 2015. Improving knowledge exchange among scientists and decision makers to facilitate the adaptive governance of marine resources: a review of knowledge and research needs. Ocean Coast. Manag. 112, 25-35.

Dangerman, A.T.C.J., Schellnhuber, H.J., 2013. Energy systems transformation. Proc. Natl. Acad. Sci. U. S. A. 110, E549-E558.

Eicken, H., Ritchie, L.A., Barlau, A., 2011. The role of local, indigenous knowledge in Arctic offshore oil and gas development, environmental hazard mitigation, and emergency response. In: Lovecraft, A.L., Eicken, H. (Eds.), North by 2020: Perspectives on Alaska's Changing Social-ecological Systems. University of Alaska Press, Fairbanks, Alaska, USA, pp. 579-605.

Elliff, C.I., Kikuchi, R.K., 2015. The ecosystem service approach and its application as a tool for integrated coastal management. Nat. Conserv. 13, 105-111.

Fabinyi, M., Evans, L., Foale, S.J., 2014. Social-ecological systems, social diversity, and power: insights from anthropology and political ecology. Ecol. Soc. 19.

Farley, J., Voinov, A., 2016. Economics, socio-ecological resilience and ecosystem services. J. Environ. Manag. 183, 389-398.

Farrell, B.H., Twining-Ward, L., 2004. Reconceptualizing tourism. Ann. Tourism Res. 31, 274-295.

Fath, B.D., Dean, C.A., Katzmair, H., 2015. Navigating the adaptive cycle: an approach to managing the resilience of social systems. Ecol. Soc. 20.

Fazey, I., Evely, A.C., Reed, M.S., Stringer, L.C., Kruijsen, J., White, P.C.L., Newsham, A. Jin, L.X., Cortazzi, M., Phillipson, J., Blackstock, K., Entwistle, N., Sheate, W., Armstrong, F., Blackmore, C., Fazey, J., Ingram, J., Gregson, J., Lowe, P., Morton, S., Trevitt, C., 2013. Knowledge exchange: a review and research agenda for environmental management. Environ. Conserv. 40, 19-36.

Fennell, D.A., Dowling, R.K., 2003. Ecotourism Policy and Planning. Centre for Agriculture and Biosciences International Publishing. Cromwell Press, Trowbridge, UK.

Forys, E.A., Allen, C.R., 2002. Functional group change within and across scales following invasions and extinctions in the everglades ecosystem. Ecosystems 5, 339-347.

Francis, P., 2015. Laudato si: On care for our common home. Our Sunday Visitor Publishing, Huntington, Indiana, USA.

Garmestani, A.S., Allen, C.R., Benson, M.H., 2013. Can law foster social-ecological resilience? Ecol. Soc. 18.

Garmestani, A.S., Allen, C.R., Cabezas, H., 2009. Panarchy, adaptive management and governance: policy options for building resilience. Neb. Law Rev. 87, 1036-1054.

Garmestani, A.S., Benson, M.H., 2013. A framework for resilience-based governance of social-ecological systems. Ecol. Soc. 18.

Goerner, S.J., Fiscus, D., Fath, B.D., 2015. Using energy network science (ENS) to connect resilience with the larger story of systemic health and development. Emergence Complex. Organ. 17, 1-21.

Gormezano, L.J., Rockwell, R.F., 2013. What to eat now? Shifts in polar bear diet during the ice-free season in western Hudson Bay. Ecol. Evol. 3, 3509-3523.

Gotts, N.M., 2007. Resilience, panarchy, and world-systems analysis. Ecol. Soc. 12.

Green, O.O., Garmestani, A.S., Allen, C.R., Gunderson, L.H., Ruhl, J.B., Arnold, C.A., Graham, N.A.J., Cosens, B., Angeler, D.G., Chaffin, B.C., Holling, C.S., 2015. Barriers and bridges to the integration of social-ecological resilience and law. Front. Ecol. Environ. 13, 332-337.

Groffman, P., Baron, J., Blett, T., Gold, A., Goodman, I., Gunderson, L., Levinson, B., Palmer, M., Paerl, H., Peterson, G., Poff, N., Rejeski, D., Reynolds, J., Turner, M., Weathers, K., Wiens, J., 2006. Ecological thresholds: the key to successful environmental management or an important concept with no practical application? Ecosystems 9, 1-13.

Guerrero, A.M., Wilson, K.A., 2017. Using a social-ecological framework to inform the implementation of conservation plans. Conserv. Biol. 31, 290-301.

Gunderson, L., Holling, C.S., 2002. Panarchy: Understanding Transformations in Human and Natural Systems. Island Press, Washington, D.C.

Holling, C.S., 1973. Resilience and stability of ecological systems. Annu. Rev. Ecol. Systemat. 4, 1-23.

Holling, C.S., 1986. The resilience of terrestrial ecosystems: local surprise and global change. In: Clarkand, W.C., Munn, R.E. (Eds.), Sustainable Development of the Biosphere: Interactions between the World Economy and the Global Environment. Cambridge University Press, Cambridge, UK, pp. 292-317.

Hollingshead, A.B., 1940. Human ecology and human society. Ecol. Monogr. 10, 354-366.

Hunsicker, M.E., Kappel, C.V., Selkoe, K.A., Halpern, B.S., Scarborough, C., Mease, L., Amrhein, A., 2016. Characterizing driver-response relationships in marine pelagic ecosystems for improved ocean management. Ecol. Appl. 26, 651-663.

Joerin, J., Shaw, R., Takeuchi, Y., Krishnamurthy, R., 2014. The adoption of a climate 
disaster resilience index in Chennai, India. Disasters 38, 540-561.

Karkkainen, B.C., 2005. Panarchy and adaptive change: around the loop and back again. Minn. J. Law Sci. Technol. 7, 59-77.

Kendall, J.K., Brooks, J., Campbell, C., Wedemeyer, K., Coon, C., Warren, S., Auad, G., Thurston, D., Cluck, R., Mann, F., Randall, S., Storzer, M., Johnston, D., MeyerPietruszka, D., Haller, M., 2017. Use of traditional knowledge by the United States Bureau of Ocean Energy Management to support resource management. Czech Polar Rep. 7, 151-163.

Kettle, N.P., Trainor, S.F., Loring, P.A., 2017. Conceptualizing the science-practice interface: lessons from a collaborative network on the front-line of climate change. Front. Environ. Sci. 5, 1-9.

Kharrazi, A., Fath, B.D., Katzmair, H., 2016. Advancing empirical approaches to the concept of resilience: a critical examination of panarchy, ecological information, and statistical evidence. Sustain. Basel 8.

Kok, M., Ludeke, M., Lucas, P., Sterzel, T., Walther, C., Janssen, P., Sietz, D., de Soysa, I., 2016. A new method for analysing socio-ecological patterns of vulnerability. Reg. Environ. Change 16, 229-243.

Kotzee, I., Reyers, B., 2016. Piloting a social-ecological index for measuring flood resilience: a composite index approach. Ecol. Indicat. 60, 45-53.

Kueker, G.D., Hall, T.D., 2011. Resilience and community in the age of world-system collapse. Nat. Cult. 6, 18-40.

Lachapelle, P.R., McCool, S.F., Patterson, M.E., 2003. Barriers to effective natural resource planning in a "messy" world. Soc. Nat. Resour. 16, 473-490.

Laterra, P., Barral, P., Carmona, A., Nahuelhual, L., 2016. Focusing conservation efforts on ecosystem service supply may increase vulnerability of socio-ecological systems. PLoS One 11.

Leuteritz, T.E.J., Ekbia, H.R., 2008. Not all roads lead to resilience: a complex systems approach to the comparative analysis of tortoises in arid ecosystems. Ecol. Soc. 13

McCarty, J.J., Canziani, O.F., Leary, N.A., Dokken, D.J., White, K.S., 2001. Climate Change 2001: Impacts, Adaptation, and Vulnerability. Contribution of Working Group II to the Third Assessment Report of the Intergovernmental Panel on Climate Change. Cambridge University Press, New York, USA.

Mead, E., Gittelsohn, J., Kratzmann, M., Roache, C., Sharma, S., 2010. Impact of the changing food environment on dietary practices of an Inuit population in Arctic Canada. J. Hum. Nutr. Diet. 23, 18-26.

Mori, A.S., Furukawa, T., Sasaki, T., 2013. Response diversity determines the resilience of ecosystems to environmental change. Biol. Rev, 88, 349-364.

Mumby, P.J., Hastings, A., Edwards, H.J., 2007. Thresholds and the resilience of Caribbean coral reefs. Nature 450, 98-101.

Orts, E.W., 1994. Reflexive Environmental Law, vol. 89. Northwestern University Law Review, pp. 1227-1340.

Osenberg, C.W., Schmitt, R.J., 1996. Detecting ecological impacts caused by human activities. In: Schmitt, R.J., Osenberg, C.W. (Eds.), Detecting Ecological Impacts; Concepts and Applications in Coastal Habitats. Academic Press, San Diego, California, USA, pp. 3-16.

Ostrom, E., 1998. Scales, polycentricity, incentives: designing complexity to govern complexity. In: Guruswamy, L.D., Mc Neely, J. (Eds.), Protection of Global Diversity: Converging Strategies. Duke University Press, Durham, NC, pp. 149-167.

Pachauri, R., Allen, M.R., Barros, V.R., Broome, J., Cramer, W., Christ, R., Church, J.A., Clarke, L., Dahe, Q., Dasgupta, P., Dubash, N.K., 2014. Climate Change 2014: Synthesis Report. Contribution of Working Groups I, II and III to the Fifth Assessment Report of the Intergovernmental Panel on Climate Change, Geneva, Switzerland.

Prugh, L.R., Hodges, K.E., Sinclair, A.R.E., Brashares, J.S., 2008. Effect of habitat area and isolation on fragmented animal populations. Proc. Natl. Acad. Sci. U. S. A. 105,
20770-20775.

Ramirez, R., Wilkinson, A., 2016. Strategic Reframing: the Oxford Scenario Planning Approach. Oxford University Press, Oxford, UK.

Reid, H., Fig, D., Magome, H., Leader-Williams, N., 2004. Co-management of contractual national parks in South Africa: lessons from Australia. Conserv. Soc. 2, 377-409.

Rockstrom, J., Steffen, W., Noone, K., Persson, A., Chapin, F.S., Lambin, E.F., Lenton, T.M., Scheffer, M., Folke, C., Schellnhuber, H.J., Nykvist, B., de Wit, C.A., Hughes, T., van der Leeuw, S., Rodhe, H., Sorlin, S., Snyder, P.K., Costanza, R., Svedin, U., Falkenmark, M., Karlberg, L., Corell, R.W., Fabry, V.J., Hansen, J., Walker, B., Liverman, D., Richardson, K., Crutzen, P., Foley, J.A., 2009. A safe operating space for humanity. Nature 461, 472-475.

Ruhl, J.B., 2012. Panarchy and the law. Ecol. Soc. 17.

Ruhl, J.B., Stuart Chapin III, F., 2013. Ecosystem services, ecosystem resilience, and resilience of ecosystem management policy. In: Allen, C.R., Garmestani, A.S. (Eds.), Resilience and Law. Columbia University Press, New York, USA, pp. 1-22.

Schultz, L., Folke, C., Osterblom, H., Olsson, P., 2015. Adaptive governance, ecosystem management, and natural capital. Proc. Natl. Acad. Sci. U. S. A. 112, 7369-7374.

Scott, C.A., Buechler, S.J., 2013. Iterative driver-response dynamics of human-environment interactions in the Arizona-Sonora borderlands. Ecosphere 4.

Silliman, B.R., Dixon, P.M., Wobus, C., He, Q., Daleo, P., Hughes, B.B., Rissing, M., Willis, J.M., Hester, M.W., 2016. Thresholds in marsh resilience to the Deepwater Horizon oil spill. Nat. Sci. Rep. 6.

Stojanovic, T., Mcnae, H.M., Tett, P., Potts, T.W., Reis, J., Smith, H.D., Dillingham, I., 2016. The "social" aspect of social-ecological systems: a critique of analytical frameworks and findings from a multisite study of coastal sustainability. Ecol. Soc. 21.

Tamis, J.E., de Vries, P., Jongbloed, R.H., Lagerveld, S., Jak, R.G., Karman, C.C., Van de Wal, J.T., Slijkerman, D.M.E., Klok, C., 2016. Toward a harmonized approach for environmental assessment of human activities in the marine environment. Integr. Environ. Assess. 12, 632-642.

Thompson, M., 2017. The wheels on the bus go round and round: innovation cycles in technological evolution. In: Winiwarter, V. (Ed.), Ecologies of Innovation, KIOES Opinions 6. Commission for Interdisciplinary Ecological Studies, Vienna, Austria, pp. 9-19.

Ulanowicz, R.E., Goerner, S.J., Lietaer, B., Gomez, R., 2009. Quantifying sustainability: resilience, efficiency and the return of information theory. Ecol. Complex. 6, 27-36.

van Apeldoorn, D.F., Kok, K., Sonneveld, M.P.W., Veldkamp, T., 2011. Panarchy rules: rethinking resilience of agroecosystems, evidence from Dutch dairy-farming. Ecol. Soc. 16 .

Vargas-Moreno, J.C., Fradkin, B., Emperador, S., Lee, O.E., 2016. Prioritizing Science Needs through Participatory Scenarios for Energy and Resource Development on the North Slope and Adjacent Seas, Boston, Massachusetts, USA. pp. 1-30.

Walker, B.H., Carpenter, S.R., Rockstrom, J., Crepin, A.S., Peterson, G.D., 2012. Drivers, "slow" variables, "fast" variables, shocks, and resilience. Ecol. Soc. 17.

Warner, K., 2011. Environmental change and migration: methodological considerations from ground-breaking global survey. Popul. Environ. 33, 3-27.

Williams, B.K., Brown, E.D., 2012. Adaptive Management: the US Department of the Interior Applications Guide, Washington, D.C.

Willis, K.J., Bailey, R.M., Bhagwat, S.A., Birks, H.J.B., 2010. Biodiversity baselines, thresholds and resilience: testing predictions and assumptions using palaeoecological data. Trends Ecol. Evol. 25, 583-591.

Yurkowski, D.J., Ferguson, S.H., Semeniuk, C.A.D., Brown, T.M., Muir, D.C.G., Fisk, A.T. 2016. Spatial and temporal variation of an ice-adapted predator's feeding ecology in a changing Arctic marine ecosystem. Oecologia 180, 631-644. 